TI 2009-003/3

Tinbergen Institute Discussion Paper

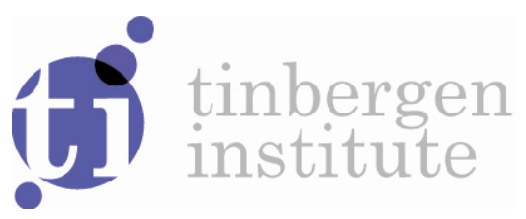

\title{
Firm Formation with Complementarities: The Role of the Entrepreneur
}

Version 3

Christian Roess/er

Philipp Koellinger ${ }^{2}$

\footnotetext{
${ }^{1}$ Dept. of Economics, Rice University and School of Economics, University of Queensland, Australia;

${ }^{2}$ Erasmus School of Economics, Erasmus University Rotterdam, and Tinbergen Institute, The Netherlands.
} 
Tinbergen Institute is the graduate school and research institute in economics of Erasmus University Rotterdam, the University of Amsterdam and VU University Amsterdam.

More TI discussion papers can be downloaded at http://www.tinbergen.nl

Tinbergen Institute has two locations:

Tinbergen Institute Amsterdam

Gustav Mahlerplein 117

1082 MS Amsterdam

The Netherlands

Tel.: +31(0)205251600

Tinbergen Institute Rotterdam

Burg. Oudlaan 50

3062 PA Rotterdam

The Netherlands

Tel.: +31(0)10 4088900

Fax: +31(0)104089031

Duisenberg school of finance is a collaboration of the Dutch financial sector and universities, with the ambition to support innovative research and offer top quality academic education in core areas of finance.

DSF research papers can be downloaded at: http://www.dsf.nl/

Duisenberg school of finance

Gustav Mahlerplein 117

1082 MS Amsterdam

The Netherlands

Tel.: +31(0)20 5258579 


\title{
Entrepreneurship, Firm Creation \& Organizational Design
}

\author{
Christian Roessler* $\quad$ Philipp Koellinger ${ }^{\dagger}$
}

July 26, 2011

\begin{abstract}
We model entrepreneurship and the emergence of firms as a result of simultaneous bidding for labor services among heterogeneous agents. Unique to our approach is that occupational choices, job matching and organizational forms are determined simultaneously, so that the opportunity costs of entrepreneurs are accounted for. We find that (1) individuals who are relatively unmanageable become entrepreneurs; (2) entrepreneurs compete against each other and create value by building efficient organizations and offering potentially very well paid jobs for others; and (3) entry of an additional entrepreneur typically reduces some individual wages, but always raises the average wage and depresses the average incomes of incumbent entrepreneurs - strictly so if the new firm partially imitates existing organizations. Our results shed a new light on the role of entrepreneurs in the economy and may be applied to explain low returns to self-employment.
\end{abstract}

JEL: L26, J24, J31, D20, L23

How talent is allocated to jobs in the labor market greatly affects the productivity of firms and economies. One aspect of this is the basic "occupational choice" - the decision whether to run ones own firm or to seek employment elsewhere. Intuitively, this choice requires that an individual compares the prospects as an entrepreneur and the income that be could earned in

*Department of Economics, Brown University. E-mail: christian_roessler@brown.edu.

${ }^{\dagger}$ Erasmus School of Economics, Erasmus University Rotterdam, The Netherlands and Tinbergen Institute, Rotterdam, The Netherlands. E-mail: koellinger@ese.eur.nl. 
employment. Thus, one should become an entrepreneur if the anticipated profit is more attractive than the going wage. The occupational choice literature (Lucas [22], Kihlstrom and Laffont [16], Evans and Jovanovic [10], Laussel and Le Breton [19]) generally treats the entrepreneurial payoff as a random variable or a function of personal characteristics, and the wage as an exogenously fixed alternative.

There are three problems with this approach, which this paper is meant to address. (1) Empirically, it is a well-established fact that entrepreneurs tend to earn less, not more, than comparable employees. For example, Hamilton [13] found for the US that staying in a salaried job, or returning to it, pays better than self-employment in the short and in the long run (except for entrepreneurs in the highest income quartile). (2) What jobs are availabe and what they pay depends on which firms come into existence; hence, the opportunity cost of becoming an entrepreneur is not independent of who does become an entrepreneur. (3) If prospective entrepreneurs have valuable skills, why are they not rewarded by potential employers?

To resolve these issues, a theoretical model of entrepreneurship needs to endogenize wages and allow them to be sensitive to individual characteristics. The literature on job matching (Kelso and Crawford [15], Roth [28], Farrell and Scotchmer [11], Ma [23], Hatfield and Milgrom [14]) partially meets these criteria. It constructs personalized wages through a sequential bidding process, where the productive contribution of a worker in a firm is unique and potentially depends on co-workers. However, what makes these models unattractive to study entrepreneurship is that the firms and their technologies are taken as given, and assumptions (e.g. workers are substitutes) are imposed somewhat arbitrarily. One does not learn in these models who becomes an entrepreneur and how it affects the types of technologies that will actually be observed.

In this paper, we model occupational choice and job matching simultaneously: Entrepreneurship is chosen if that is preferable to the best job offered by others who are becoming entrepreneurs. In equilibrium, individuals who can create more value under their own management than under the management of someone else will become entrepreneurs. In other words, the distinctive characteristics of entrepreneurs in our model is that they are all relatively unmanagable. They may or may not earn high incomes and create high value as entrepreneurs, but, in equilibrium, they will not have the option to work for someone else for the same or a better income. Furthermore, we show that the competition among entrepreneurs forces them to create ef- 
ficient organizations. This allows them to hire and occupy workers such that the value that is created and the wages that can be offered are maximized. Our entrepreneurs implement the technology that is most productive given their own characteristics and the characteristics of their potential workforce, which may entail substantial complementarities between workers in the resulting equilibrium firms.

The technologies and organizational structures that are going to be operated in equilibrium are uniquely determined by individual characteristics and may involve both complement and substitute relationships between workers. The latter has some important implications for some of the standard supplyand-demand relationships in the labor market: Normally, if labor supply is fixed, an increase in the demand for labor should increase wages (e.g. as the result of the arrival of an additional entrepreneur in the market). However, we show that this is only true if workers are substitutes. When workers are complements, the opposite can happen: Additional entrepreneurs can lead to smaller firms with less productive employees, which will decrease the wages of some employees. However, we also show that the entry of an additional entrepreneur must still raise wages on average because the losses of some employees will be compensated by the gains of others. It is important to understand that this is not at all obvious unless one imposes a priori that workers are substitutes.

Hence, the characteristics of the population do not only determine occupational choices and which firms come into existence, they also determine the wage structure and how it compares to entrepreneurial profits. Specifically, our model also allows for populations with a high share of relatively unmanagable individuals who would choose to become entrepreneurs (because they would have no better employment alternatives available). In such populations, the typical wage may well exceed the typical profit as a consequence of individually optimal behavior under complete information. We illustrate this possibility with an example later in the paper and thereby offer an alternative explanation for Hamilton's [13] empirical results.

The next section describes the model, assumptions about primitive values (conditional productivities $v_{i j}$ ), and the nature of equilibrium. The primitive values we admit include anything that could be derived from a spatial model, where agents are associated with points in $\mathbb{R}^{n}$ (e.g. professional characteristics) and the value one individual can create under another's management declines in the interpersonal distance. Then we discuss the unique membership and organization of equilibrium firms in Section 2. They can be obtained 
from the primitives by a simple algorithm. Subsequently, in Section 3, we study the equilibrium payoff distribution between entrepreneurs and wage earners. We show that a greater number of entrepreneurs leads to (weakly) higher wages and (weakly) lower incomes for the incumbent entrepreneurs. When entrepreneurial entry is imitative (copies part of an existing organization structure), these effects are strict. The possibility that entrepreneurial incomes fall short of the average wage is illustrated by a simple numerical example in Section 4. In Section 5, we discuss how complement and substitute relationships between workers arise endogenously. Proofs are collected in the appendix.

\section{The Model}

In our model, firm $F_{i}$ operates production function

$$
y_{i}=\sum_{j \in F_{i}} v_{k j} .
$$

The value $v_{k j}$ is employee $j$ 's output when working under manager $k$. The overall output of the firm is therefore the sum of individual outputs given assignments to managers.

This generalizes the standard Cobb-Douglas form to hierarchical organizations $F_{i}$ with heterogeneous workers. With

$$
y_{i}=A K_{i}^{\alpha}\left(\sum_{j \in F_{i}} v_{k j}\right)^{1-\alpha}
$$

and a financial market in which entrepreneurs can borrow capital at rate $r$, optimal borrowing implies

$$
K_{i}=\left(\frac{1}{r} \alpha A\right)^{1 /(1-\alpha)} \sum_{j \in F_{i}} v_{k j}
$$

thus

$$
y_{i}-r K_{i}=(1-\alpha)\left(\frac{1}{r} \alpha\right)^{\alpha /(1-\alpha)} A^{1 /(1-\alpha)} \sum_{j \in F_{i}} v_{k j}
$$


The multiplier $(1-\alpha)\left(\frac{1}{r} \alpha\right)^{\alpha /(1-\alpha)} A^{1 /(1-\alpha)}$ is immaterial to our analysis, as long as any idiosyncratic productivity is subsumed in the $v_{k j}$. Therefore, we ignore the multiplier and capital expenditures below and focus on the characteristics of the population, $v_{k j}$.

Verbally, the model works as follows. There is a finite population of agents. For any pair of agents $i$ and $j$, there is a primitive value $v_{i j}$ that reflects the output that $j$ can create under $i$ 's supervision. The value $v_{i j}$ is realized if $j$ is assigned to $i$ ("is managed by $i$ ") in the organization structure their employer (the entrepreneur) implements. We assume perfect information. The game is a simultaneous auction where every agent submits a wage bid to every other agent, self included. Preferences are purely monetary and all agents accept the highest bid they receive. If the highest bid is their own, they become entrepreneurs and otherwise employees. Hence, all agents are potential entrepreneurs who can create firms by successfully bidding for employees (including themselves) in the labor market. The wages they offer are based on the worker's expected productivity in their firms, taking into account who else is being hired and available as a manager. Potential entrepreneurs compete for employees based on organization designs: in calculating their wage bids, they plan to build a particular kind of organization that affects labor productivity through the managerial assignments. In equilibrium, occupational choice, firm membership, organization structure and incomes arise endogenously.

\subsection{Conditional Productivities}

There are $N$ agents in the economy. The conditional productivity of employee $j$ under manager $i$ is $v_{i j} \in \mathbb{R}_{+}$and commonly known. ${ }^{1}$ This is the profit (before subtracting wages) that $j$ can generate for the firm if the entrepreneur assigns $i$ as $j$ 's manager. Since the conditional productivity is exogenous, it is not affected by how many, and which, other individuals $i$ manages, or

\footnotetext{
${ }^{1}$ It is possible to decentralize the hiring process and lessen information and coordination requirements. E.g. in a corresponding network formation game, employees would create links with their managers, rather than let themselves be hired and assigned by the entrepreneur. Then, no single agent needs to know all conditional productivities; when agents meet, merely one of them has to recognize the value that could be created in a relationship.
} 
by who manages $i$. It also does not depend on the wage $j$ is paid. This need not mean that there is no principal-agent problem. The conditional productivities may reflect, in addition to $j$ 's skill at the job and $i$ 's skill at designing tasks, how willingly $j$ exerts effort and how well $i$ monitors. If effort were unobservable, $v_{i j}$ could be interpreted as $j$ 's expected performance under the optimal contract. ${ }^{2}$

We rule out equal conditional productivities under different managers in the interest of efficient notation. The restriction is plausible if the primitive values are drawn from a continuous distribution with a positive mean. This implies that, for everyone, there is some manager who elicits strictly positive productivity.

We also impose a noncircularity axiom that amounts to transitivity of managerial ability: if $i$ can increase the productivity of $j$ (by managing $j$ ), and $j$ can increase someone else's productivity (by managing them), then $i$ should also be able to increase that person's productivity as a manager. One way to interpret this axiom is that if $j$ creates more value under $i$ 's management than working independently, then perhaps $i$ is more knowledgeable about the task they perform. This reading suggests that $j$ is not an effective manager for $i$. We extend this logic to chains $v_{i j} \geq v_{j j}, v_{j k} \geq v_{k k}, \ldots, v_{l m} \geq$ $v_{m m}$. We require that the first agent creates more value independently than under the management of the last, i.e. $v_{i i} \geq v_{m i}$. This property implies that hierarchical organizations emerge in equilibrium. Such hierarchical organizations have the desirable property that circular authority cannot occur, so that one can clearly identify the entrepreneurs (i.e. those at the top of an organization) and the employees (i.e. those below the entrepreneur).

Axiom: Noncircularity. For any indexing $t: N \rightarrow\{1,2, \ldots, n\}$ of agents, if $v_{t(t+1)} \geq v_{(t+1)(t+1)}$ for all $t \leq T$, then $v_{11} \geq v_{(T+1) 1}$.

Noncircularity could be replaced by a stronger "positive agency cost" axiom: for all $i, j \in N, v_{i i} \geq v_{i j}$, i.e. $i$ can manage self more effectively than others. This statement implies noncircularity, e.g. $v_{i j} \geq v_{j j}$ and $v_{j k} \geq v_{k k}$ lead to $v_{i i} \geq v_{i j} \geq v_{j j} \geq v_{j k} \geq v_{k k} \geq v_{k i}$. Positive agency cost is plausible when management is top-down ( $i$ sets tasks for $j$ without seeking $j$ 's advice), and delegation may result in a loss from communication barriers and partial effort. The role of $j$ is then merely to carry out instructions as closely as possible.

\footnotetext{
${ }^{2}$ This interpretation can be supported as long as the expected wage cost of inducing a given increase in $v_{i j}$ varies only with $j$, but not with the identity of the manager $i$.
} 
In applications, it may be meaningful to infer conditional productivities from distances between points associated with the individuals. These points could be attributes in a social or professional characteristics space, where distances represent communication barriers or skill mismatch. Positive agency cost is satisfied by values that are spatial in the following sense: there exists a mapping $f: N \rightarrow \mathbb{R}^{l}$ and a distance metric $d: N \times N \rightarrow \mathbb{R}$ such that, for all $i, j, k \in N, v_{i j} \geq v_{i k}$ if and only if $d(f(i), f(j)) \leq d(f(i), f(k))$. To verify that positive agency cost (and therefore noncircularity) holds, note simply that $d(f(i), f(i))=0 \leq d(f(i), f(j))$ for all $j \in N$, so that $v_{i i} \geq v_{i j} .{ }^{3}$

\subsection{Non-Cooperative Game}

The conditional productivities $v_{i j}$ are the economy's data. We define now strategy spaces and our equilibrium notion, which is a refinement of Nash's. A manager assignment is a function $r_{i}: N \times 2^{N} \rightarrow N$ such that $r_{i}(j, C) \in C$. It identifies whom $i$ would assign to manage, $j \in C .{ }^{4}$ Let $R_{i}$ be the set of such functions. Wage offers are a function $w_{i}: N \rightarrow \mathbb{R}_{+}$that specifies a bid for everyone's labor services (including $i$ 's own). Let $W_{i}$ be the set of such functions. Employer choice is a function $e_{i}: \mathbb{R}_{+}^{n} \rightarrow N$ which names, for every set of offers $w_{1}(i), w_{2}(i), \ldots, w_{n}(i)$ to $i$, the bidder $j \in N$ whose offer is accepted (possibly $j=i$ ). Let $E_{i}$ be the set of such functions. ${ }^{5}$

\footnotetext{
${ }^{3}$ The converse, that conditional productivities consistent with positive agency cost are spatial, is not true. For example, let (1) $v_{i i}>v_{i j}>v_{i k}$, (2) $v_{j j}>v_{j k}>v_{j i}$, (3) $v_{k k}>$ $v_{k i}>v_{k j}$. While (1) and (3) would imply $d(f(i), f(j))<d(f(i), f(k))<d(f(j), f(k))$, (2) requires $d(f(j), f(k))<d(f(i), f(j))$. By extension, noncircularity is also strictly more general than the "spatial property."

${ }^{4}$ Notation is loose here. The domain of the function is implicity restricted to pairs $(i, C) \in N \times 2^{N}$ with $i \in C$.

${ }^{5}$ Several properties are implicit in the domains of these functions. The assignment of unique managers, in conjunction with noncircular valuations, implies that organization charts are trees. Holding multiple jobs is ruled out. Employer choice, as we have defined it, precludes a preference for working under specific managers. In practice, the best-paid job is not always chosen. It may be desirable to work with the supervisor that makes the agent most productive. (Dutta and Masso [8] study preferences over colleagues.) One may prefer to be one's own boss. A network of social and family relations may affect the benefits of a job. In our economy, social considerations are absent, i.e. job offers are evaluated only on wages.

A subtle restriction is hidden in the form of the wage offers. In general, $i$ would like to offer a schedule of wages to each $j \in N$ that depends on the offers $j$ is making. Then $i$ can reward $j$ for competing less aggressively in the labor market. In particular, $i$ would
} 
Given a strategy profile $s \in \times_{i \in N} S_{i}$ (where $S_{i}=R_{i} \times W_{i} \times E_{i}$ ), a firm $F_{i}(s)$ consists of those inividuals who select $i$ as their employer:

$$
F_{i}(s)=\left\{j \in N \text { s.t. } e_{j}(w)=i\right\}
$$

We use letters without subscripts to denote profiles, e.g. $w \equiv\left\{w_{i}\right\}_{i \in N}$ is the set of all wage offers. Since everyone accepts exactly one wage offer, the collection of firms in the economy is a partition of $N$. Some firms may well be empty: if $F_{i}(s)=\varnothing$, we will call $i$ an employee; if $F_{i}(s) \neq \varnothing, i$ is an entrepreneur.

The profit that accrues to $i$ is the difference between the value created in $i$ 's firm and the wages paid:

$$
\pi_{i}(s)=\sum_{j \in F_{i}(s)} v_{r_{i}\left(j, F_{i}(s)\right) j}-\sum_{j \in F_{i}(s)} w_{i}(j) .
$$

Obviously, the value created depends on managerial assignments in the firm. Therefore, an important aspect of maximizing entrepreneurial profits is to create organizational structures and managerial assignments that maximize the value that can be created. Note that the income of entrepreneurs, i.e. $i \in F_{i}(s)$, is invariant to the wages they pay themselves: $w_{i}(i)+\pi_{i}(s)$ is constant with respect to $w_{i}(i)$. Nevertheless, wage offers to self matter in a technical sense: they determine whether or not $i$ becomes self-employed. The invariance applies only after this choice is made.

Definition: Market. The labor market is a game $\Gamma=\left(N,\left\{v_{i j}\right\}_{i, j \in N}, \times_{i \in N} S_{i},\left\{u_{i}\right\}_{i \in N}\right)$, with strategy space $S_{i}=R_{i} \times W_{i} \times E_{i}$ for each $i \in N$, conditional productivities that satisfy noncircularity, and preferences represented by a utility function $u_{i}: \mathbb{R} \rightarrow \mathbb{R}^{+}$that increases monotonically in income $w_{e_{i}(w)}(i)+\pi_{i}(s)$ for all $i \in N$.

We treat $\Gamma$ as a normal-form game: strategies are chosen simultaneously. In particular, every $i \in N$ plans the internal structure of any firm $i$ may run, makes wage offers to all $j \in N$, and decides how to select among wage offers $i$ will receive.

prevent any employee $j$ from making the best alternative bid for another of $i$ 's employees $k$, increasing $k$ 's bargaining power with $i$. To this end, $i$ would offer $j$ a higher wage if $j$ bids zero for $k$. Because we do not allow such tie-ins (by forcing offers to be in $\mathbb{R}_{+}$), competing bids for $i$ 's employees may come from within $i$ 's firm. Internal competition, from potential spin-offs, is important in practice. 
A solution of $\Gamma$ is a Nash equilibrium in undominated pure strategies that leads to well-structured firms in a sense we will explain. Strategy $s_{i} \in S_{i}$ is undominated if there exists no $s_{i}^{\prime} \in S_{i}$ such that $u_{i}\left(s_{i}^{\prime}, s_{-i}\right) \geq u_{i}\left(s_{i}, s_{-i}\right)$ for all $s_{-i} \in \times_{j \in N \backslash\{i\}} S_{j}$, and $u_{i}\left(s_{i}^{\prime}, s_{-i}\right)>u_{i}\left(s_{i}, s_{-i}\right)$ for some $s_{-i} \in \times_{j \in N \backslash\{i\}} S_{j}$. That is, if $s_{i}$ is not weakly dominated by, and in some situation strictly worse than, another strategy.

The rationale for ruling out equilibria in (weakly) dominated strategies is that agents can otherwise offer wages they are not prepared to pay, knowing they will be outbid. Entrepreneurs would have to pay unreasonably high wages - but might refuse to do so, in which case the overbidders would want to withdraw their offers. Such equilibria seem unstable.

In principle, two employees of a firm could be assigned to manage each other at the same time. This type of arrangement is problematic: no final authority would exist to resolve coordination failures. One might conjecture that $i$, as the designer of firm $F_{i}(s)$, would not adopt such a structure, unless it is strictly profitable to do so. Hence we focus on equilibria where, in each firm, only one individual reports to self. Moreover, in $F_{i}(s)$, it seems reasonable that this individual should be $i{ }^{6}$

Definition: Strict Ordering Assignment. Manager assignment $r_{i}$ is a strict ordering if, for all $i, j \in N, r_{i}\left(j, F_{i}(s)\right)=j$ only if $i=j$.

Strict ordering assignments are not an assumption, but a refinement property of equilibria. We eliminate no strategies and require solutions to be Nash equilibria on the full domain of the strategy space $\times_{i \in N} S_{i} .{ }^{7}$ Not joining $F_{i}(s)$ or choosing a partial ordering assignment for $F_{i}(s)$, which are unilateral deviations for $i$, cannot be payoff-improving in an equilibrium for any $i \in N$.

Given all of the above, an equilibrium in our game is defined as follows:

Definition: Equilibrium. Strategy profile $s^{*} \in \times_{i \in N} S_{i}$ is an equilibrium of $\Gamma$ if, for every $i \in N, s_{i}^{*}$ is undominated, $r_{i}^{*}$ is a strict ordering, and $u_{i}\left(s_{i}^{*}, s_{-i}^{*}\right) \geq u_{i}\left(s_{i}^{\prime}, s_{-i}^{*}\right)$ for all $s_{i}^{\prime} \in S_{i}$.

\footnotetext{
${ }^{6}$ If we only impose that there is a unique individual, not necessarily $i$, who reports to self in $F_{i}(s)$, we get permutations of firm names. The membership and structure of $F_{i}(s)$ migrate to $F_{k}(s)$ in alternate equilibria. Payoffs would not be affected, but the division of entrepreneurial incomes into wages and profits would then be restricted.

${ }^{7}$ The reason is partly technical: since strict ordering requires $i \in F_{i}(s)$ or $F_{i}(s)=\varnothing$, $i$ could not make offers without committing to be an entrepreneur if the restriction were applied to the strategy space.
} 


\section{Firms}

Associated with an equilibrium $s^{*}$ is a partition of $N$ into firms $F_{i}\left(s^{*}\right)$. In this section we derive the unique membership and organization of the equilibrium firms. The requirement that equilibrium play is undominated imposes a few specific constraints. First, entrepreneurs always assign the best available manager to each employee. Second, workers join the firm that makes the highest wage offer to them. ${ }^{8}$ Formally:

Lemma (P1). For all $i \in N, s_{i} \in S_{i}$ is an undominated strategy only if:

(i) for all $C \subseteq N$ and all $j \in C, r_{i}(j, C)=h$ only if $v_{h j} \geq v_{k j}$ for all $k \in C$;

(ii) $e_{i}(w)=h \neq i$ only if $w_{h}(i) \geq w_{k}(i)$ for all $k \in N \backslash i .^{9}$

Proof. p. 24.

Furthermore, given the strict ordering requirement that only entrepreneurs can be assigned to themselves, they must join their own firms if they hire any employees in equilibrium:

Lemma (P2). For all $i \in N$, if $F_{i}\left(s^{*}\right) \neq \varnothing$, then $i \in F_{i}\left(s^{*}\right)$.

Proof. p. 24.

We now introduce a notation that greatly simplifies the characterization of equilibria in our model: Intuitively, firms will be blocks of complementary individuals who can create value, i.e. effectively manage each other, independently of outsiders. Equilibrium firms can be characterized in terms of the set of individuals for whom $i$ induces the highest productivity (is the ideal manager),

$$
G_{i}=\left\{j \in N \text { s.t. } v_{i j} \geq v_{k j} \text { for all } k \in N\right\},
$$

and its transitive closure,

$$
\bar{G}_{i}=\left\{\begin{array}{c}
j \in N \text { s.t., for some }\left\{k_{1}, k_{2}, \ldots, k\right\} \subseteq N, \\
k_{1} \in G_{i}, k_{2} \in G_{k_{1}}, \ldots, j \in G_{k}
\end{array}\right\} .
$$

\footnotetext{
${ }^{8}$ That is, individuals accept the highest wage conditional on becoming workers. It must exceed a reservation level that reflects the option to be self-employed and contribute to value creation in one's own firm. Else, they become entrepreneurs.

${ }^{9}$ To be clear, the function $e_{i}$ selects, for every possible set of wage offers $i$ might receive, an employer. Hence, (ii) is not conditional on actual wage offers received in equilibrium. It requires $i$ to commit to accept the highest offer whenever $i$ does not become an entrepreneur.
} 
The latter is the set of individuals whose ideal manager is someone whose ideal manager is someone ... whose ideal manager is $i$. The ideal assignment of the entire population could be visualized as a group of trees, each branching out from an individual who is her own ideal manager (a likely entrepreneur) to members of "upper management" whose ideal manager is an entrepreneur, to members of "middle management" whose ideal manager is in upper management, etc. $\bar{G}_{i}$ contains everyone "under $i$," the subtree that begins with $i$. Lemma (P3) establishes that equilibrium firms in our model will indeed be such trees of complementary individuals:

Lemma (P3). For all $i, j, j^{\prime} \in N$ such that $i \neq j \neq j^{\prime} \neq i$,

(i) $G_{i} \cap G_{j}=\varnothing$;

(ii) $G_{i} \subseteq \bar{G}_{i}$;

(iii) if $j \in \bar{G}_{i}$, then (a) $i \notin G_{j}$, (b) $i \notin \bar{G}_{j}$, (c) $j \notin \bar{G}_{j}$, (d) $\bar{G}_{j} \subset \bar{G}_{i}$;

(iv) $\bar{G}_{i} \cap \bar{G}_{j}=\varnothing$ or $\bar{G}_{i} \subset \bar{G}_{j}$ or $\bar{G}_{j} \subset \bar{G}_{i}$, and if $j, j^{\prime} \in G_{i}$, then $\bar{G}_{j} \cap \bar{G}_{j^{\prime}}=\varnothing$;

(v) $G_{i} \cup \bigcup_{j \in G_{i}} \bar{G}_{j}=\bar{G}_{i}$.

Proof. p. 24.

If $j$ belongs to the firm $F_{i}\left(s^{*}\right)$ (where possibly $i=j$ ), then $j$ 's complementary block $\bar{G}_{j}$ can create more value in $F_{i}\left(s^{*}\right)$ than anywhere else, since the ideal managers for members of $\bar{G}_{j}$ are themselves in $\bar{G}_{j} \cup j$. Hence, $j$ 's employer is able to make the highest bid for $\bar{G}_{j}$ :

Lemma (P4). For all $i, j \in N$, if $j \in F_{i}\left(s^{*}\right)$, then $\bar{G}_{j} \subseteq F_{i}\left(s^{*}\right)$.

Proof. p. 25.

We can now describe membership in equilibrium firms in terms of the complementary blocks.

Proposition (P5). For all $i \in N$, either $F_{i}\left(s^{*}\right)=\varnothing$ or $F_{i}\left(s^{*}\right)=\bar{G}_{i}$.

Proof. p. 27.

Nothing in P5 prevents firms from being empty. In particular, $F_{i}\left(s^{*}\right)=\varnothing$ if $i \notin \bar{G}_{i}$, i.e. (by P3ii) if $i \notin G_{i}$. The firms partition $N$ since $x \in \bar{G}_{i}$ and $i \in G_{i}$ imply $x \in \bar{G}_{j}$ only if $\bar{G}_{j} \subset \bar{G}_{i}$ (by inductive application of P3iiid).

The structure of the complementary blocks suggests a simple algorithm to solve for equilibrium firms. We define a function $f^{0}: N \rightarrow N$ that maps to $i \in N$ the individual under whose management $i$ is most productive.

$$
f^{0}(i)=j \text { s.t. } v_{j i} \geq v_{k i} \text { for all } k \in N .
$$


Iterations $f^{t+1}(i)=f\left(f^{t}(i)\right)$ successively assign to $i$ the ideal manager, the ideal manager of $i$ 's ideal manager, etc. The sequence $\left\{f^{t}\right\}_{t \in \mathbb{N}}$ converges because $N$ is finite and conditional productivities are noncircular. Its limit, $f^{\infty}=f^{t}$ such that $f^{t}=f^{t+1}$, ranges over the set of individuals who are their own ideal managers. These are the entrepreneurs. One can express the firm run by $i$ as

$$
F_{i}\left(s^{*}\right)=\left\{j \in N \text { s.t. } f^{\infty}(j)=i\right\} .
$$

On the basis of P5, we can say more about the equilibrium organization of firms. Since $j \in F_{i}\left(s^{*}\right)$ only if the largest complementary block that includes $j$ is in $F_{i}\left(s^{*}\right), j$ 's ideal manager, $k$ such that $j \in G_{k}$, is available. P1 says that $k$ must then be chosen to manage $j$ by all undominated strategies, hence in any equilibrium.

Proposition (P6). In any equilibrium, for all $i \in N$ and $j \in F_{i}\left(s^{*}\right)$, $r_{i}^{*}\left(j, F_{i}\left(s^{*}\right)\right)=k$ such that $j \in G_{k}$.

Proof. p. 28.

This strengthens P1i (which entails that only assignments to the best manager within the firm are undominated) to the statement that, in equilibrium firms, employees are assigned to the best manager in the entire population. Hence, P6 ensures that equilibria are efficient: everyone is optimally assigned and creates the greatest possible value. Hence, potential entrepreneurs compete against each other by building efficient organizations that maximize the value created in the entire society. In our view, this is the essential role of entrepreneurs in the economy. By doing so, entrepreneurs create jobs for others that maximize the value everyone can generate, taking personal characteristics and fit with others in society into account.

Notice that in this welfare maximizing equilibrium, the optimal share of entrepreneurs in society also arises endogenously and it depends entirely on the distribution of personal characteristics $v_{i j}$. Thus, more entrepreneurs are not necessarily better, but for every society, there exists an optimal share of entrepreneurs that creates exactly those entreprises and organizational structures that maximize the value that can be generated. 


\section{Incomes}

\subsection{Earnings of Entrepreneurs}

Like the organization structure, the division of income in a firm between the entrepreneur and the workforce is uniquely determined. Entrepreneurs have no preference between receiving their income in wages or profits; all that matters are the combined receipts. Let $v_{(1) i}, v_{(2) i}, \ldots$ denote the highest, second-highest, etc. productivity $i$ has under the potential managers in the population.

Proposition (P7). In any equilibrium $s^{*}$, for all $i \in N$ such that $F_{i}\left(s^{*}\right) \neq \varnothing$ (i.e. for all entrepreneurs),

$$
w_{e_{i}^{*}\left(w^{*}\right)}^{*}(i)+\pi_{i}\left(s^{*}\right)=v_{(1) i}+\sum_{j \in G_{i} \backslash i}\left(v_{(1) j}-v_{(2) j}\right) .
$$

Proof. p. 28.

Hence, the income of entrepreneur $i$ equals the value $i$ creates under his own management, plus the sum of the wedges between the value that $i$ 's direct subordinates create in $i$ 's firm and the value they would create in the firms of their respective second highest bidders. This result is intuitive: Because the entrepreneur makes ultimatum wage offers, he can appropriate all benefits he directly bestows on the firm. Workforce income in firm $F_{i}\left(s^{*}\right)$ is the difference between total value created in $F_{i}\left(s^{*}\right)$ and the entrepreneurial income.

Importantly, employees as a group appropriate all value that is created below the highest level of managers, that reports directly to entrepreneurs. Since the value created further down in the hierarchy depends only on employees, other entrepreneurs could replicate it in their firms by hiring complementary groups and recreating their previous assignments in the new firm. In particular, anyone can employ the entire workforce of an existing firm and will only lose some productivity among the "top managers" that depended on the old entrepreneur. This is in one sense a peculiarity of our modeling choices because we restricted a manager's impact to the organization level immediately below. While this is not descriptively realistic, it captures the flavor of how value appropriation works in hierarchical organizations. One 
can imagine how a leader who "inspires" employees at all levels of the firm could reap large returns, but the essential constraints would remain the same.

We show in the next section that an equilibrium exists, by constructing an explicit equilibrium wage function for the employees. There are, however, many ways to allocate workforce income among employees: entrepreneurs are indifferent between wage offer schemes that leave the firm's profit unaffected. It is not necessarily true that the entrepreneur must pay every worker a wage that reflects the productive contribution to the firm. A wage increase for a group of employees reduces its incentive to defect and may therefore permit offsetting wage decreases for other employees (who could otherwise profitably attract the group through a unilateral change in wage offers). Hence there is no reason why equilibrium wages should be unique. Such redistributions must, however, leave the total wage bill of the firm unchanged. Which wage scheme to implement is a matter of choice, not coincidence, given that the entrepreneur makes the offers.

\subsection{Entrepreneurial Entry and the Average Wage}

Now, consider adding a new agent to the population, transforming the economy from the prior game $\Gamma$ to the posterior game $\hat{\Gamma}$. We speak of entrepreneurial entry when the new arrival is an entrepreneur in the posterior game and increases the number of entrepreneurs by one (else, it would reflect an acquisition of an existing firm). Hence, entrepreneurial entry does not replace any of the previous entrepreneurs: we are interested in the effect a growing number of entrepreneurs (equivalently, increasing demand in the labor market).

Let $O \equiv\left\{i \in N\right.$ s.t. $\left.F_{i}\left(s^{*}\right) \neq \varnothing\right\}$ be the set of entrepreneurs, with $\hat{N}$ and $\hat{O}$ denoting, respectively, the population and the set of entrepreneurs after entry.

Proposition (P8). Entrepreneurial entry increases the average employee wage: if $\hat{N}=N \cup\{h\}$ and $h \in \hat{M}$, then

$$
\frac{1}{\|N\|-\|O\|} \sum_{i \in N \backslash O} w_{e_{i}^{*}\left(w^{*}\right)}^{*}(i) \leq \frac{1}{\|\hat{N}\|-\|\hat{O}\|} \sum_{i \in \hat{N} \backslash \hat{O}} \hat{w}_{\hat{e}_{i}^{*}\left(\hat{w}^{*}\right)}(i) .
$$

At the same time, entrepreneurial entry decreases the average income of 
incumbent entrepreneurs:

$$
\frac{1}{\|O\|} \sum_{i \in O}\left(w_{i}^{*}(i)+\pi_{i}\left(s^{*}\right)\right) \leq \frac{1}{\|O\|} \sum_{i \in O}\left(\hat{w}_{i}^{*}(i)+\hat{\pi}_{i}\left(s^{*}\right)\right) .
$$

Proof. p. 29.

The intuition for rising average wages is more straightforward than the details. The additional entrepreneur increases competition in the labor market by introducing new jobs that represent alternative uses of each individuals' labor services. Some employees are likely to lose in the reassignment of workers, since their managerial capacities are in less demand. Suppose $i$ is an employee who switches to the new entrepreneur. Her former manager was able to appropriate some of $i$ 's productivity in the old firm. After $i$ 's departure, the old firm becomes the best alternative employer for $i$, and $i$ must therefore appropriate in the new firm the full value she created in the old firm. This includes the share her former manager is losing in wages there. Hence, all wage reductions are at least offset by raises for the new entrepreneur's hires.

In specific circumstances, additional entrepreneurs strictly increase employee wages. We say that imitative entrepreneurial entry by $h$ occurs if $h \notin N$ and there exists, for some entrepreneur $i \in N$, an agent $j \in G_{i}$ ( $i$ 's employee and direct subordinate in the prior game's equilibrium $s^{*}$ ) who switches to $h$, i.e. $j \in \hat{G}_{h}$. Such entry is imitative in the sense that $h$ effectively hires a "branch" of the incumbent firm $F_{i}\left(s^{*}\right)$; the firm $F_{h}\left(\hat{s}^{*}\right)$ partially replicates the organization of $F_{i}\left(s^{*}\right)$.

Proposition (P9). The average employee wage strictly increases (and average income of incumbent entrepreneurs strictly decreases) when imitative entrepreneurial entry occurs.

Proof. p. 30.

When one of the new entrepreneur's hires is a "top manager" of an existing firm (which is implicit in acquiring a branch), then the manager who loses by the transfer is in fact an entrepreneur. The top manager now appropriates in her new wage the full contribution she made to the old firm (else the previous employer would sufficiently raise the bid to convince her to stay). Because part of it previously did not accrue to employees, average employee income goes up. This explains P9. 
The wage increase may be strict even if entrepreneurship is not imitative, since the new entrepreneur could raise the highest alternative productivity for a top manager who nevertheless stays with the old firm. This makes it necessary for the employer to raise the employee's wage.

\section{Relative Payoffs: Employees vs. Entrepre- neurs}

The expected monetary return to entrepreneurship is generally found to be low or negative compared to wage income. Overly optimistic beliefs (Camerer and Lovallo [5], Koellinger et al. [17], Arabsheibani et al. [1], de Meza and Southey [7], Frank [12]) or inherent preference for entrepreneurship (Benz and Frey [2], Blanchflower et al. [3]) have been advanced as explanations. ${ }^{10}$ Vereshchagina and Hopenhayn [30] recently argued that entrepreneurs may effectively behave in a risk-seeking manner, even if they are risk-averse with respect to consumption. ${ }^{11}$

We offer a rationale for lower entrepreneurial incomes that is not a consequence of imperfect information or preferences. Competition in the labor market forces entrepreneurs to invent roles for employees that maximize their productivities, hence their value to the firm. Entrepreneurs thereby raise their own "opportunity costs" in the form of well-paid jobs for workers. ${ }^{12}$

\footnotetext{
${ }^{10}$ There is also an "investment view" (Bohacek [4], Polkovnichenko [24]) according to which entrepreneurs initially forego income in the expectation of large future rewards. But it seems inconsistent with Hamilton's observation that entrepreneurial firms, on average, underperform relative to entry-level wages even after long periods of operation.

${ }^{11}$ Their entrepreneurs choose a lottery over business outcomes that, absent capital markets, will either allow them to continue to operate (if things turn out well) or force them to close down and become workers later. Occupations have different wealth needs. If the entrepreneur stays in business, income is reinvested and has high marginal utility. If the entrepreneur fails, income is used for consumption and has lower marginal utility. Ex ante, an entrepreneur then prefers a risky lottery (either a very profitable business or lower consumption as a worker in the future) to intermediate levels of wealth (running a relatively unprofitable business or enjoy higher consumption as a worker). The low risk premium can be attributed to the fact that entrepreneurs actually like risky business outcomes.

${ }^{12}$ To be sure, these are not the true opportunity costs, but they are the opportunity costs empirical work imputes, since we can only match entrepreneurs to a reference group of employees using relatively coarse information. People who look comparable in the dataset may actually differ in ways that would be obvious to a recruiter. Then entrepreneurs are not choosing low returns over higher wages; they simply cannot get those wages, although
} 
We can illustrate with a small-scale example how the average income of entrepreneurs can be strictly lower than the average wage employees earn in equilibrium. Recall that equilibrium wages are not unique because income can be redistributed among the employees of a firm. Such redistributions do not change average wages, since entrepreneurial incomes are uniquely identified. However, for tangibility we derive a particular equilibrium wage function and use it in the example.

Proposition (P10). There exists an equilibrium $s^{*}$ where the wage offers accepted by $i=1, \ldots, N$ (including entrepreneurs) are ${ }^{13}$

$$
w_{e_{i}^{*}\left(w^{*}\right)}^{*}(i)=v_{(2) i}+\sum_{j \in G_{i}}\left(v_{(1) j}-v_{(2) j}\right) .
$$

Proof. p. 31.

The maximal value created by workers in $\bar{G}_{i}$ for the firm $F_{h}\left(s^{*}\right)$ depends solely on $i$; not on $i$ 's manager, or even the entrepreneur $h$. This suggests the solution derived in P10: everyone is paid the incremental profit made under his or her managerial supervision (by the group $G_{i}$ for whom $i$ is the best manager) since that profit could be transferred to another firm (if $i$ is hired together with $i$ 's complementary block $\bar{G}_{i}$ ). Hence, managers receive, for each worker they manage, the wedge between the worker's productivity and what that productivity would have been under the best alternative manager. In addition, they get their own productivity under the best alternative manager (which informs the second-highest bid for their services). As natural as this arrangement may appear, it is certainly not the only one that can occur in equilibrium; the entrepreneur can make transfers between workers, since the complementarity structure only makes it optimal to leave the firm as long as other workers have the same incentive.

Consider the following conditional productivities for individuals $x, y$ and $z$. Value $v_{x y}$ (that $y$ can generate under the management of $x$ ) is found

the data might suggest they can. Rees and Shah [26] have produced empirical support for the contention that existing high-pay jobs are not necessarily available to those who choose to be entrepreneurs.

${ }^{13}$ Given that entrepreneurs pay themselves the "market wage," i.e. their opportunity cost, entrepreneurial profit is the difference between the value they create under selfmanagement and what they would create under the next-best manager: $\pi_{i}\left(s^{*}\right)=v_{(1) i}-$ $v_{(2) i}$. 
where the $y$-row (listing $y$ 's productivity under various managers) meets the $x$-column (listing $x$ 's managerial contribution to various employees).

\begin{tabular}{ll||c|c|c|} 
Employer & & $x$ & $y$ & $z$ \\
\hline \hline \multirow{2}{*}{ Employee } & $x$ & 0 & 7 & 2 \\
\cline { 2 - 5 } & $y$ & 0 & 1 & 2 \\
\cline { 2 - 5 } & $z$ & 0 & 1 & 2 \\
\hline
\end{tabular}

In equilibrium, all agents are assigned to the manager under whom they are most productive (a feature of efficient organizations) and to the firm which employs the best manager. Hence, $x$ must be managed by $y$, while $y$ must be managed by $z$. There is one firm in equilibrium: the entrepreneur $z$ hires $y$ and $x$, and assigns $y$ as $x$ 's manager. Agent $z$ emerges as an entrepreneur because he can generate more value under his own management than under the management of anyone else. Hence, $z$ is relatively unmanageable but turns out to be a better manager for $y$ than $y$ is for himself. According to the equilibrium wage function in P10, $x$ will earn 2 (reflecting his best alternative productivity, under $z$ ), $y$ will earn 6 (including the difference of 5 between $x$ 's productivity under $y$ and under $z$ ), and $z$ will pay himself a wage of 2 (including the difference of 1 between $y$ 's productivity under $z$ and under $y$ ) and earn a residual profit of 1 . Average employee income is 4, compared to the entrepreneurial income of 3 . (That entrepreneurial income is lower, as in this case, is a possibility, depending on primitives, not a regularity.)

To verify that these payoffs constitute a Nash equilibrium, note that, if $z$ offered $x$ less than 2 or $y$ less than $6, y$ would have an incentive to create a firm that hires $x$ and generates a total value of 8 (which can be divided between $x$ and $y$ such that both benefit). The payoffs make $y$ exactly indifferent to the "spin-off" option, hence they maximize the entrepreneur $z$ 's income. In alternative equilibria, $z$ would transfer income from $x$ to $y$, perhaps offering $x$ nothing, while $y$ is paid 8 . Or $x$ could be offered 7 , and $y$ only gets 1 .

What is common to all equilibria is that the entrepreneur $z$ cannot extract any rent from the employment of $x$ because $x$ and $y$ could defect if they are not fully compensated for the profit they generate between themselves. Since most of the value is created by these two, average employee incomes are high relative to the entrepreneur's. Yet, $z$ can do no better than to run his own business.

Now consider the entry of an additional entrepreneur $e$, leaving all other conditional productivities unaffected. 


\begin{tabular}{cc||c|c|c|c|} 
Employer & & $x$ & $y$ & $z$ & $e$ \\
\hline \hline \multirow{3}{*}{ Employee } & $x$ & 0 & 7 & 2 & 0 \\
\cline { 2 - 6 } & $y$ & 0 & 1 & 2 & 3 \\
\cline { 2 - 6 } & $z$ & 0 & 1 & 2 & 0 \\
\cline { 2 - 6 } & $e$ & 0 & 1 & 2 & 3 \\
\hline
\end{tabular}

The new agent $e$ replaces $z$ as the best manager for $y$ and becomes an entrepreneur since he is most productive working for himself. Therefore, the new firm structure consists of $e$ 's organization, which includes $y$ and $x$ (where $y$ still manages $x$ ), and $z$ as a lone self-employed entrepreneur. Because $e$ adopts part of the organization structure formerly implement by $z$ (copies $z$ 's production technology), we call $e$ an imitative entrepreneur. The wage for $y$ under the equilibrium given by P10 increases from 6 to 7 because the new bid raises the best alternative offer for $y$ (which is now $z$ 's), while $x$ 's wage remains unaffected (given that $e$ has no direct use for $x$ ). The entry of the imitative entrepreneur bids up the average wage from 4 to 4.5 owing to the greater competition for scarce production resources: $e$ 's technology is intensive in the same kind of labor as $z$ 's. Among the entrepreneurs, $e$ earns 4 (highest productivity under an alernative manager plus the wedge of 1 from superior management of $y$ and residual profit 1 ), and $z$ loses income he was previously able to appropriate from $y$ : $z$ 's wage of 1 is complemented by a profit of 1 . Incumbent entrepreneurial income therefore declines to 2 (while average entrpreneurial income remains the same).

Finally, suppose $e$ enters with an innovative idea, which causes him to implement a "novel" production technology that is intensive in $x$ 's labor.

\begin{tabular}{cc||c|c|c|c|} 
Employer & & $x$ & $y$ & $z$ & $e$ \\
\hline \hline \multirow{3}{*}{ Employee } & $x$ & 0 & 7 & 2 & 8 \\
\cline { 2 - 6 } & $y$ & 0 & 1 & 2 & 0 \\
\cline { 2 - 6 } & $z$ & 0 & 1 & 2 & 0 \\
\cline { 2 - 6 } & $e$ & 0 & 1 & 2 & 3 \\
\hline
\end{tabular}

Compared to the original scenario (without $e$ ), $e$ replaces $y$ as the best manager for $x$, while $z$ remains the best manager for himself and for $y$. Thus, two firms emerge in equilbrium: $e$ hires $x$, and $z$ hires $y$. Now $x$ benefits from $e$ 's arrival; his wage increases by 5 from 2 to 7 (since $z$ now makes the second-highest bid, based on $z$ 's productivity under the management of $z$ 's employee $y$ ). Because $y$ no longer manages $x, y$ loses the wedge of 5 he could 
formerly extract from managing $x$. The total wage bill in the economy here is unchanged by $e$ 's entry; the increase in $x$ 's wage matches exactly the decrease in $y$ 's wage. This is a reflection of the equilibrium property that the workforce fully appropriates any value created below the top-management level. Since entry only changes the productivity of $x$, who was previously managed by an employee and therefore shared the value with an employee, $x$ 's reassignment merely induces a transfer between employees. The income of entrepreneur $z$ also remains constant because $z$ could not previously extract rents from employing $x$; $z$ had to compensate $y$ fully for his managerial skills. However, since $e$ attains a higher income than $z$ (namely 4, including the managerial contribution of 1 to $y$ 's productivity, and profit of 1 ), entrepreneurial incomes here increase on average after entry.

This example illustrates that average wage increases when the number of entrepreneurs increases, where innovative entry yields the minimal case that average wage stays the same. The average income of incumbent entrepreneurs decreases (again, it may be constant when entry is innovative), while the average income of all entrepreneurs could increase or decrease, depending on the value the entrant creates for himself. Here, entrepreneurial activity raises its own opportunity cost to a point where entrepreneurial incomes are on average lower than wages (this was the case in all three scenarios).

While it may seem unrealistic that entrepreneurs tend to have relatively little value as employees, our model certainly allows for entrepreneurs to be potential high earners in employment. But the empirical fact that entrepreneurs earn less on average than non-entrepreneurs is more consistent with many entrepreneurs having relatively poor earning prospects in traditional employment. For entrepreneurs who are professionals or skilled inventors, this may not be the case, but there is another type of entrepreneur who never acquired experience in employment or specific training and is stuck in self-employment. Our framework accommodates both types, not by assumption but by endogenous determination. Together, the self-selection of relatively unmanageable types into entrepreneurship and market incentives to create valuable jobs for others suggest why the relative payoff to entrepreneurship is low in countries with large shares of entrepreneurs, such as the United States. 


\section{Equilibrium Technology: Complements vs. Substitutes}

In standard job matching models, workers are either substitutes or complements by assumption. In the salary adjustment process Kelso and Crawford [15] proposed, the best offer to a given worker must be repeated in the following round, while others may raise their bids. The central premise behind this approach is that firms will not want to withdraw a successful offer to one worker when competition for other workers intensifies. Hence the worker's value to the firm must not be diminished if co-workers are lost. Earlier, Crawford and Knoer [6] assumed that employee productivity is invariant to who else joins the firm. Kelso and Crawford [15] generalized to the "gross substitutes" property, which is imposed in a number of subsequent studies (e.g. Roth [28] and Ma [23]). Workers are gross substitutes if higher salary offers to one do not adversely affect firms' willingness to hire the other.

Complementarity has been introduced through economies of scale that depend only on the number of workers the firm employs (Farrell and Scotchmer [11]) and through supermodularity (Sherstyuk [29]). ${ }^{14}$ A new hire makes existing employees more valuable, and the size of the externality increases with every additional worker. Then no two workers are substitutes (and the symmetric nature of the complementarity raises the question whether firms would merge if they were not exogenously seperate). ${ }^{15}$

\footnotetext{
${ }^{14}$ A related kind of complementarity appears in Kremer's [18] model of interdependent production tasks. Here, the likelihood of completing a job successfully increases in the skill of co-workers at their roles. A skilled individual bestows a symmetric externality on all colleagues. One implication that is not echoed in our model is that similarly skilled individuals tend to be hired into the same firms.

In Rosen's [27] firms, the most skilled individuals are employed as managers and confer productive externalities on lower-level workers. A key difference with us is that the externality in Rosen depends only on the identity of the manager, not the worker. In fact, our agents cannot necessarily be ranked by "skill," since complementarities are specific to pairs. Two individuals may be highly effective managers in most cases, but not work well with each other. However, Rosen's explanation of high salaries for top managers, stemming from these hierarchical complementarities, partially carries over, since firms have an incentive to assign managers selectively to make them as productive as possible.

${ }^{15}$ Pycia [25] derives a stable matching with complementarities if the equilibrium satisfies pairwise alignment: two members of a firm jointly benefit or jointly lose from adding any group of workers. This is a property of equilibrium payoffs that are, in Pycia's model (not ours), determined after workers are matched to firms. It does not hold in our setting, which differs in several respects (e.g. endogenous firms).
} 
But these relationships are not really arbitrary. Entrepreneurs have an incentive (and face competitive pressure) to build optimal organizations that, in some sense, maximize complementarities. Because individuals are not uniformly suited to work together and manage, the firm's profitability depends on how each role is staffed. Profitability under different staffing scenarios determines the wage offers a prospective entrepreneur can make, and thus whether he or she is ultimately successful in recruiting a workforce and starting a firm.

Whether a given pair are complements or substitutes is in our approach an aspect of the equilibrium organization technology, not a fundamental property. The coexistence of substitute and complement workers is made possible through the introduction of hierarchical organization forms. That it should be so is quite intuitive: the different roles in a firm are complementary, real substitutability only exists within a role. E.g. for a building company, different architects may be substitutes, whereas an architect and a construction worker are complements. Two workers are complements in our model if they interact at different levels of the hierarchy: one is assigned to manage the other. On the other hand, they are substitutes if they compete on the same level of the hierarchy: one can replace the other as manager of a given group of employees.

Suppose firm $h$ increases its wage offer for employee $j$ of equilibrium firm $F_{i}\left(s^{*}\right)$. In case the wage offer is large enough to attract $j$ to $F_{h}\left(s^{*}\right)$, the effect on an employee $k \neq j$ of $F_{i}\left(s^{*}\right)$ can be of two kinds: $k$ 's value added to $F_{i}\left(s^{*}\right)$ may weakly increase (making $j$ and $k$ substitutes) or weakly decrease (complements). If $k$ leaves $F_{i}\left(s^{*}\right)$, then the value created by the group $G_{k} \subseteq F_{i}\left(s^{*}\right)$ is diminished, since $k$ is the best manager for its members. Also, the value of $j \in F_{i}\left(s^{*}\right)$ with $k \in G_{j}$ is diminished, since $j$ is no longer required as the best manager for $k$. These are complement effects. On the other hand, $j$ could replace $k$ as managers for the individuals in $G_{k}$, if $j$ is the best alternative manager for such an individual within the firm. This is a substitute effect.

\section{Conclusion}

The choice to become an entrepreneur is usually modelled independently from the matching of non-entrepreneurs to jobs. Since job roles determine wages, and wages represent the opportunity cost of entrepreneurship, occu- 
pational choice and job matching are in reality determined simultaneously. Our framework accounts for this. Rather than assume a particular technology where workers are either substitutes or complements, we recognize that entrepreneurs have an incentive to delegate by building hierarchical organizations, where employees perform quasi-entrepreneurial tasks (i.e. become executives) and are rewarded for their talents. Managerial assignments lead to rich internal patterns of complementary and substitute relationships among employees. ${ }^{16}$

We derive a unique wealth-sharing rule between entrepreneurs and workers in a unique firm formation equilibrium and show that more entrepreneurs imply a higher average wage income. While this is intuitive when workers are substitutes, job switching in the presence of complementarities imposes losses on co-workers. For example, when the star of a new director rises in Hollywood, the race to sign top actors intensifies. Another director is forced to cast lesser names and accept a less lucrative contract. Who you work with affects your value to your employer: hence, McKinsey pays the highest salaries in the consulting industry, and consultants in second-tier firms earn less, even if they are of similar quality. Simple supply-and-demand economics might suggest that greater demand (a world with McKinsey, compared to without) will not reduce anyone's wages while supply is fixed. Yet, if McKinsey disappeared, it is a fair guess that second-tier firms could hire better consultants who would raise their colleagues' productivities and pay.

When complementarities are present, because firms have internal organization, the arrival of a new entrepreneur is not good news for all workers. The reasoning that the additional employer can only increase the highest conditional productivity for each worker, and thus individual wages, does not apply when productivities depend on organization designs, which are broken up by entry. Entrepreneurial entry will reduce wages for some workers. What survives, and is robust to the specific pattern of complementarities that arises in equilibrium, is that the average wage increases with entrepreneurial entry. Hence, high salaries and relatively low returns to entrepreneurship are a hallmark of an entrepreneurial sector that builds efficient organizations and delegates valuable tasks to employees.

Our view of the role of entrepreneurs in the economy also offers an al-

\footnotetext{
${ }^{16}$ Delegation leads to a departure from the logic in Lazear [20], [21], where more flexible individuals necessarily become entrepreneurs. In an equilibrium with organization choice, one can benefit from managerial skills as an employee.
} 
ternative explanation to Hamilton's [13] empirical finding of relatively low incomes among entrepreneurs: We find that those people who become entrepreneurs are relatively unmanageable, i.e. they create more value working for themselves than for others. This implies that entrepreneurs do not, as usually assumed, have the outside option to switch back to equally or better paid wage jobs.

\section{Proofs}

\section{P1}

(i) Replacing any $r_{i}$ with an optimal assignment of managers, i.e. $r_{i}(j, C)=$ $h$ such that $v_{h j} \geq v_{k j}$ for all $k \in C$, can only be beneficial, and one may construct opposing strategy profiles $s_{-i}$ against which it is a strict improvement over any suboptimal assignment. (Specifically, let the person who is suboptimally assigned join $F_{i}(s)$.) If $i$ accepts someone else's wage offer, then $i$ 's payoff increases directly with a higher wage.

(ii) Suppose $i$ 's strategy is to turn down a higher wage offer from another individual for a lower wage offer from another individual for some particular set of offers $\tilde{w}_{-i}$. Clearly, an alternative strategy that always accepts the highest wage offer, conditional on $i$ taking a job in another firm (not becoming an entrepreneur), never fares worse and strictly improves $i$ 's payoff in case $\tilde{w}_{-i}$ is played.

\section{P2}

Let $F_{i}\left(s^{*}\right) \neq \varnothing$, and suppose $i \notin F_{i}\left(s^{*}\right)$. Take any $x_{0} \in F_{i}\left(s^{*}\right)$, and label $k$ such that $r_{i}^{*}\left(x_{0}, F_{i}\left(s^{*}\right)\right)=k$ as $k=x_{1}, l$ such that $r_{i}^{*}\left(x_{1}, F_{i}\left(s^{*}\right)\right)=l$ as $l=x_{2}$, etc. Consider the sequence $\left\{x_{t}\right\}_{t \in \mathbb{N}}$. Because $F_{i}\left(s^{*}\right)$ is finite, it must be that $r_{i}^{*}\left(x_{t+\theta}, F_{i}\left(s^{*}\right)\right)=x_{t}$ for some $t$ and some non-negative integer $\theta$. Since assignments are hierarchical, and $i \notin F_{i}\left(s^{*}\right)$, there exists no $x_{t} \in F_{i}\left(s^{*}\right)$ such that $r_{i}^{*}\left(x_{t}, F_{i}\left(s^{*}\right)\right)=x_{t}$. Hence $\theta$ is not zero. P1i requires $r_{i}^{*}\left(x_{t+\theta}, F_{i}\left(s^{*}\right)\right)=x_{t}$ only if $v_{x_{t} x_{t+\theta}} \geq v_{y x_{t+\theta}}$ for all $y \in F_{i}\left(s^{*}\right)$. In particular $v_{x_{t} x_{t+\theta}} \geq v_{x_{t+\theta} x_{t+\theta}}$, which conflicts with noncircularity and uniqueness.

\section{P3}


(i) Uniqueness guarantees that $v_{i x} \geq v_{k x}$ for all $k \in N$ only if there exists no $j \in N, j \neq i$, such that $v_{j x} \geq v_{k x}$ for all $k \in N$. Hence if $x \in G_{i}$, then $x \notin G_{j}$.

(ii) If $j \in G_{i}$, then $j \in \bar{G}_{i}$ is immediate from the definition of $\bar{G}_{i}$.

(iii) If $j \in \bar{G}_{i}$, then there exists a sequence $\left\{k_{1}, k_{2}, \ldots, k\right\} \subseteq N$ such that $k_{1} \in G_{j}, k_{2} \in G_{k_{1}} \ldots j \in G_{k}$. Thus $v_{i k_{1}}>v_{k_{1} k_{1}}, v_{k_{1} k_{2}}>v_{k_{2} k_{2}} \ldots v_{k j}>v_{j j}$ (uniqueness makes the inequalities strict). Applying noncircularity, we have $v_{i i}>v_{j i}$.

Hence it is not the case that $v_{j i} \geq v_{k i}$ for all $k \in N$, i.e. (a) $i \notin G_{j}$. If $i \in \bar{G}_{j}$, then $v_{j i}>v_{i i}$, which is also a contradiction, so (b) $i \notin \bar{G}_{j}$. If $j \in \bar{G}_{j}$, then $v_{j j} \geq v_{k j}$ for all $k \in N$; in particular $v_{j j} \geq v_{i j}$, which is at odds with $j \in G_{i} \subseteq \bar{G}_{i}$ and uniqueness. Thus (c) $j \notin \bar{G}_{j}$. Let $x \in \bar{G}_{j}$. Then either $x \in G_{j}$ or there exists a sequence $\left\{k_{1}^{\prime}, k_{2}^{\prime}, \ldots, k^{\prime}\right\} \subseteq N$ such that $k_{1}^{\prime} \in G_{j}$, $k_{2}^{\prime} \in G_{k_{1}^{\prime}} \ldots x \in G_{k^{\prime}}$. In both cases, $j \in \bar{G}_{i}$ implies there is a sequence $\left\{l_{1}, l_{2}, \ldots, l\right\} \subseteq N$ such that $j \in G_{i}, l_{1} \in G_{j}, l_{2} \in G_{l_{1}} \ldots x \in G_{l}$. Therefore $x \in \bar{G}_{i}$. So (d) $\bar{G}_{j} \subseteq \bar{G}_{i}$, and by (ii) and (iiic) $j$ is in $\bar{G}_{i}$ but not in $\bar{G}_{j}$, so the inclusion is strict.

(iv) Suppose there exists $x \in \bar{G}_{i} \cap \bar{G}_{j}$. Then there are sequences $K=$ $\left\{k_{1}, k_{2}, \ldots, k\right\} \subseteq N$ such that $k_{1} \in G_{j}, k_{2} \in G_{k_{1}} \ldots x \in G_{k}$ and $K^{\prime}=$ $\left\{k_{1}^{\prime}, k_{2}^{\prime}, \ldots, k^{\prime}\right\} \subseteq N$ such that $k_{1}^{\prime} \in G_{j^{\prime}}, k_{2}^{\prime} \in G_{k_{1}^{\prime}} \ldots x \in G_{k^{\prime}}$. It follows from (i) that $x \in G_{k} \cap G_{k^{\prime}} \neq \varnothing$ only if $k=k^{\prime}$ etc. Therefore $K \subseteq K^{\prime}$ or $K^{\prime} \subseteq K$, and thus either $i \in K^{\prime}$ or $j \in K$, i.e. either $i \in \bar{G}_{j}$ or $j \in \bar{G}_{i}$. By (iiid), $j \in \bar{G}_{i}$ implies $\bar{G}_{j} \subset \bar{G}_{i}$, and $i \in \bar{G}_{j}$ implies $\bar{G}_{i} \subset \bar{G}_{j}$.

If $j, j^{\prime} \in G_{i}$, suppose $\bar{G}_{j} \cap \bar{G}_{j^{\prime}} \neq \varnothing$, so that $\bar{G}_{j} \subset \bar{G}_{j^{\prime}}$ or $\bar{G}_{j^{\prime}} \subset \bar{G}_{j^{\prime}}$. In the first case, $j \in G_{i}$ implies $i \in \bar{G}_{j^{\prime}}$; in the second case, $j^{\prime} \in G_{i}$ implies $i \in \bar{G}_{j}$ either of which contradicts (iiib). We conclude $\bar{G}_{j} \cap \bar{G}_{j^{\prime}}=\varnothing$.

(v) If $j \in G_{i}, j \neq i$, then $\bar{G}_{j} \subset \bar{G}_{i}$ by (iiid). Hence $\cup_{j \in G_{i}} \bar{G}_{j} \subseteq \bar{G}_{i}$. Moreover, $G_{i} \subseteq \bar{G}_{i}$ by (ii), which establishes the $\subseteq$ part of the equality. If $x \in \bar{G}_{i}$ and $x \notin G_{i}$, then there exists $\left\{k_{1}, k_{2}, \ldots, k\right\} \subseteq N$ such that $k_{1} \in G_{i}$, $k_{2} \in G_{k_{1}} \ldots x \in G_{k}$. It follows that $x \in \bar{G}_{k_{1}}$ for some $k_{1} \in G_{i}$, or $x \notin G_{i}$. Relabeling $k_{1}$ as $j$, we have $\bar{G}_{i} \subseteq G_{i} \cup \bigcup_{j \in G_{i}} \bar{G}_{j}$.

\section{P4}

We show: for all $i, j, k \in N$, if $j \in F_{i}\left(s^{*}\right)$ and $k \in G_{j}$, then $k \in F_{i}\left(s^{*}\right)$. This implies $j \in F_{i}\left(s^{*}\right)$ only if $G_{j} \subseteq F_{i}\left(s^{*}\right)$, and we apply P3 to argue $G_{j} \subseteq F_{i}\left(s^{*}\right)$ only if $\bar{G}_{j} \subseteq F_{i}\left(s^{*}\right)$. 
Let $k \in G_{j}$, and suppose $s^{*}$ is such that $j \in F_{i}\left(s^{*}\right)$ while $k \in F_{h}\left(s^{*}\right)$, with $h \neq i$. Since $s^{*}$ is an equilibrium, the profit generated by $h$ 's employees cannot be negative:

$$
\sum_{x \in F_{h}\left(s^{*}\right) \backslash h} v_{r_{h}^{*}\left(x, F_{h}\left(s^{*}\right)\right) x}-\sum_{x \in F_{h}\left(s^{*}\right) \backslash h} w_{h}^{*}(x) \geq 0 ;
$$

else $h$ could strictly improve on $u_{h}\left(s^{*}\right)$ by offering $w_{h}(x)=0$ to all $x \in$ $F_{h}\left(s^{*}\right)$. If $h \in F_{h}\left(s^{*}\right)$, then

$$
u_{h}\left(s^{*}\right)=v_{r_{h}^{*}\left(h, F_{h}\left(s^{*}\right)\right) h}+\sum_{x \in F_{h}\left(s^{*}\right) \backslash h} v_{r_{h}^{*}\left(x, F_{h}\left(s^{*}\right)\right) x}-\sum_{x \in F_{h}\left(s^{*}\right) \backslash h} w_{h}^{*}(x) .
$$

Suppose $i$ offered every one of $h$ 's employees a slightly higher wage: $\tilde{w}_{i}(x)=w_{h}^{*}(x)+\varepsilon$ for all $x \in F_{h}\left(s^{*}\right) \backslash h$, with $\varepsilon>0$. If $h \in F_{h}\left(s^{*}\right)$, suppose $i$ also offered $h$ a wage that exceeds the current payoff: $\tilde{w}_{i}(h)=u_{h}\left(s^{*}\right)+\varepsilon$. Any employer-choice function that would reject these offers is not undominated, hence cannot be part of an equilibrium strategy. (P1ii implies $x \in F_{h}\left(s^{*}\right)$ only if $h$ offered the highest wage to $x$ in $s^{*}$. After topping the offer, $i$ must be the high bidder and gain $x$.) We show that it is in fact an improvement for $i$ to offer these wages for some $\varepsilon>0$.

The payoff for $i$ when running firm $F_{i}\left(\tilde{s}_{i}, s_{-i}^{*}\right)=F_{i}\left(s^{*}\right) \cup F_{h}\left(s^{*}\right)$ after increased offers $\tilde{w}_{i}$, with all else equal, is

$$
\begin{aligned}
u_{i}\left(\tilde{s}_{i}, s_{-i}^{*}\right) & =u_{i}\left(s^{*}\right)+\sum_{x \in F_{h}\left(s^{*}\right)} v_{r_{i}^{*}\left(x, F_{i}\left(\tilde{s}_{i}, s_{-i}^{*}\right)\right) x}-\sum_{x \in F_{h}\left(s^{*}\right)} w_{h}^{*}(x)-\sum_{x \in F_{h}\left(s^{*}\right)} \varepsilon \\
& \geq u_{i}\left(s^{*}\right)+\sum_{x \in F_{h}\left(s^{*}\right)}\left(v_{r_{i}^{*}\left(x, F_{i}\left(\tilde{s}_{i}, s_{-i}^{*}\right)\right) x}-v_{r_{h}^{*}\left(x, F_{h}\left(s^{*}\right)\right) x}-\sum_{x \in F_{h}\left(s^{*}\right)}(1)\right.
\end{aligned}
$$

if $h \notin F_{h}\left(s^{*}\right)$, and

$$
\begin{aligned}
u_{i}\left(\tilde{s}_{i}, s_{-i}^{*}\right) & =u_{i}\left(s^{*}\right)+\sum_{x \in F_{h}\left(s^{*}\right)} v_{r_{i}^{*}\left(x, F_{i}\left(\tilde{s}_{i}, s_{-i}^{*}\right)\right) x}-\sum_{x \in F_{h}\left(s^{*}\right) \backslash h} w_{h}^{*}(x)-u_{h}\left(s^{*}\right)-\sum_{x \in F_{h}\left(s^{*}\right)} \varepsilon \\
& \geq u_{i}\left(s^{*}\right)+\sum_{x \in F_{h}\left(s^{*}\right)}\left(v_{r_{i}^{*}\left(x, F_{i}\left(\tilde{s}_{i}, s_{-i}^{*}\right)\right) x}-v_{r_{h}^{*}\left(x, F_{h}\left(s^{*}\right)\right) x}-\sum_{x \in F_{h}\left(s^{*}\right)} \varepsilon\right.
\end{aligned}
$$

if $h \in F_{h}\left(s^{*}\right)$. Inequalities (4) and (5) derive, respectively, from (2) and (3).

For all $x \in F_{h}\left(s^{*}\right)$,

$$
v_{r_{i}^{*}\left(x, F_{i}\left(\tilde{s}_{i}, s_{-i}^{*}\right)\right) x} \geq v_{r_{h}^{*}\left(x, F_{h}\left(s^{*}\right)\right) x},
$$


since $F_{h}\left(s^{*}\right) \subseteq F_{i}\left(\tilde{s}_{i}, s_{-i}^{*}\right)$. Because $s_{i}^{*}$ is undominated, P1i implies that the assignment $r_{i}^{*}$ is value-maximizing. Clearly, the maximal conditional productivity for any $x \in F_{h}\left(s^{*}\right)$ must be at least as large in $F_{i}\left(\tilde{s}_{i}, s_{-i}^{*}\right)$ as in $F_{h}\left(s^{*}\right)$.

Since $k \in G_{j}$ and $j \notin F_{h}\left(s^{*}\right)$,

$$
v_{j k}>v_{r_{h}^{*}\left(k, F_{h}^{*}\right) k}
$$

On the other hand $j \in F_{i}\left(s^{*}\right) \subseteq F_{i}\left(\tilde{s}_{i}, s_{-i}^{*}\right)$, so $r_{i}^{*}\left(k, F_{i}\left(\tilde{s}_{i}, s_{-i}^{*}\right)\right)=j$ and $v_{r_{i}^{*}\left(k, \tilde{F}_{i}\right) k}=v_{j k}$. Then $u_{i}\left(\tilde{s}_{i}, s_{-i}^{*}\right) \geq u_{i}\left(s^{*}\right)$ if

$$
\varepsilon=\frac{v_{j k}-v_{r_{h}^{*}\left(k, F_{h}\left(s^{*}\right)\right) k}}{n+1}>0 .
$$

The deviation establishes that $k \in F_{h}\left(s^{*}\right)$ for any $h \neq i$ is not possible in equilibrium. Thus $k \in F_{i}\left(s^{*}\right)$, and we have demonstrated that $j \in F_{i}\left(s^{*}\right)$ leads to $G_{j} \subseteq F_{i}\left(s^{*}\right)$. Let $x \in \bar{G}_{j}$ and $x \notin G_{j}$. Then there exists $\left\{k_{1}, k_{2}, \ldots, k\right\} \subseteq N$ such that $k_{1} \in G_{j}, k_{2} \in G_{k_{1}}, \ldots, x \in G_{k}$. From $j \in F_{i}\left(s^{*}\right)$ and $k_{1} \in G_{j}$ we have $k_{1} \in F_{i}\left(s^{*}\right)$, applying our prior argument. Similarly, $k_{1} \in F_{i}\left(s^{*}\right)$ and $k_{2} \in G_{k_{1}}$ imply $k_{2} \in F_{i}\left(s^{*}\right)$. Inductively, $k_{1}, k_{2}, \ldots, k \in F_{i}\left(s^{*}\right)$, and therefore $x \in F_{i}\left(s^{*}\right)$. It follows that $j \in F_{i}\left(s^{*}\right)$ entails $\bar{G}_{j} \subseteq F_{i}\left(s^{*}\right)$.

\section{P5}

Since $i \in F_{i}\left(s^{*}\right)$ by $\mathrm{P} 2$ if $F_{i}\left(s^{*}\right) \neq \varnothing, \mathrm{P} 4$ requires $\bar{G}_{i} \subseteq F_{i}\left(s^{*}\right)$. It remains to be shown that $F_{i}\left(s^{*}\right) \subseteq \bar{G}_{i}$, or equivalently $N \backslash \bar{G}_{i} \subseteq N \backslash F_{i}\left(s^{*}\right)$. Suppose $x \in N \backslash \bar{G}_{i}$ and $x \in F_{i}\left(s^{*}\right)$. We relabel $x$ as $x_{0}$ and reconstruct the sequence $\left\{x_{t}\right\}_{t \in \mathbb{N}}$ as in the proof of P2. Observe that $i \neq x_{t}$ for any $t$; else we would have $x \in \bar{G}_{i}$. By our prior argument, $r_{i}^{*}\left(x_{t+\theta}, F_{i}\left(s^{*}\right)\right)=x_{t}$ for some $t$ and integer $\theta>0$, which violates noncircularity unless $r_{i}^{*}\left(x_{t}, F_{i}\left(s^{*}\right)\right)=x_{t}$ for some $x_{t} \in F_{i}\left(s^{*}\right) \neq i$. But this does not satisfy the hierarchy requirement. Hence $x \in N \backslash F_{i}\left(s^{*}\right)$, and we have established $F_{i}\left(s^{*}\right)=\bar{G}_{i}$.

\section{P6}

Follows from P2 and the fact that $j \in F_{i}\left(s^{*}\right)$ only if $k \in F_{i}\left(s^{*}\right)$ such that $j \in G_{k}$, which is what we have to show. If $j \in F_{i}\left(s^{*}\right)$ and $j \in G_{k}$, but 
$k \in F_{h}^{*}$ with $h \neq i$, then $j \in F_{h}^{*}$ : by P3ii $G_{k} \subseteq \bar{G}_{k}$, and by P4, $\bar{G}_{k} \subseteq F_{h}^{*}$. This contradicts the premise $j \in F_{i}\left(s^{*}\right)$.

P7

To see that

$$
w_{e_{i}^{*}\left(w^{*}\right)}^{*}(i)+\pi_{i}\left(s^{*}\right) \leq v_{(1) i}+\sum_{j \in G_{i} \backslash i}\left(v_{(1) j}-v_{(2) j}\right),
$$

note

$$
\begin{aligned}
w_{e_{i}^{*}\left(w^{*}\right)}^{*}(i)+\pi_{i}\left(s^{*}\right) & \leq \sum_{j \in F_{i}\left(s^{*}\right)} v_{r_{i}^{*}\left(j, F_{i}\left(s^{*}\right)\right) j}-\sum_{j \in F_{i}\left(s^{*}\right) \backslash i} w_{i}^{*}(j) \\
& =\sum_{j \in \bar{G}_{i}} v_{(1) j}-\sum_{j \in \bar{G}_{i} \backslash i} w_{i}^{*}(j)
\end{aligned}
$$

(the firm's profit and wages must be covered by equilibrium output).

We shall refer to $\bar{G}_{j} \cup j$ such that $j \in G_{i} \backslash i$ (i.e. $j$ is a top-level manager) as a branch of $i$ 's firm. Wage payments by $i$ to a branch must exceed the highest productivity $\bar{G}_{j} \cup j$ would have in other firms; else it would be optimal for someone else to beat $i$ 's offers to all member of $\bar{G}_{j} \cup j$. (Namely, for the employer of $j$ 's best alternative manager $j^{\prime}$. If $j^{\prime}$ is employed by $i$, then it is optimal for the employer of the best alternative manager of $j^{\prime \prime}$ 's branch "head" $k$ to beat $i$ 's offer to $\bar{G}_{j} \cup j \cup \bar{G}_{k} \cup k$. Noncircularity ensures that $i$ is ultimately constrained by competition from other entrepreneurs who have the highest alternative valuation for one branch or several branches jointly. For notational simplicity, we focus on the special case that branches can be considered separately, i.e. the best alternative manager of each branch head in $F_{i}\left(s^{*}\right)$ belongs to another firm. When best alternative managers are employees of $F_{i}\left(s^{*}\right)$ in other branches, multiple branches must be considered as one, but the logic is identical.)

The individual who is the best alternative manager for $j$ also has the second-highest valuation for $\bar{G}_{j}$ (since $\bar{G}_{j} \cup j$ includes the best managers for all members of $\bar{G}_{j}$, so that the productivity of $\bar{G}_{j} \cup j$ varies only with $j$ 's productivity). Thus, if $j \in G_{i}$ then $i$ has to pay to $\bar{G}_{j} \cup j$ in total

$$
\sum_{k \in \bar{G}_{j} \cup j} w_{i}^{*}(k) \geq v_{(2) j}+\sum_{k \in \bar{G}_{j} \backslash j} v_{(1) k} .
$$


Because $\bar{G}_{i} \backslash i=\bigcup_{j \in G_{i} \backslash i} \bar{G}_{j}$ and the $\bar{G}_{j}$ do not intersect by P3, we have

$$
\begin{aligned}
\sum_{l \in \bar{G}_{i} \backslash i} w_{i}^{*}(l) & =\sum_{j \in G_{i} \backslash i} \sum_{k \in \bar{G}_{j} \cup j} w_{i}^{*}(k) \\
& =\sum_{j \in G_{i} \backslash i} v_{(2) j}+\sum_{j \in G_{i} \backslash i} \sum_{k \in \bar{G}_{j} \backslash j} v_{(1) k}=\sum_{j \in G_{i} \backslash i} v_{(2) j}+\sum_{j \in \bar{G}_{i} \backslash G_{i}} v_{(1) j} .
\end{aligned}
$$

Now

$$
\begin{aligned}
w_{e_{i}^{*}\left(w^{*}\right)}^{*}(i)+\pi_{i}\left(s^{*}\right) & \leq \sum_{j \in \bar{G}_{i}} v_{(1) j}-\sum_{j \in G_{i} \backslash i} v_{(2) j}-\sum_{j \in \bar{G}_{i} \backslash G_{i}} v_{(1) j} \\
& =v_{(1) i}+\sum_{j \in G_{i} \backslash i}\left(v_{(1) j}-v_{(2) j}\right) .
\end{aligned}
$$

From the entrepreneur's income-maximizing behavior, it follows that the last expression holds with equality.

\section{P8}

Pre-entry total employee income is:

$$
\begin{aligned}
\sum_{i \in N \backslash O} w_{e_{i}^{*}\left(w^{*}\right)}^{*}(i) & =\sum_{i \in N} v_{(1) i}-\sum_{i \in O}\left(w_{i}^{*}(i)+\pi_{i}\left(s^{*}\right)\right) \\
& =\sum_{i \in N \backslash O} v_{(1) i}-\sum_{i \in O} \sum_{j \in G_{i} \backslash i}\left(v_{(1) j}-v_{(2) j}\right) \\
& =\sum_{i \in N \backslash \cup_{j \in O} G_{j}} v_{(1) i}+\sum_{i \in \cup_{j \in O} G_{j} \backslash j} v_{(2) j} .
\end{aligned}
$$

Post-entry, the set of employees is unchanged and highest- and secondhighest conditional productivities for any agent either stay the same or are raised by the new entrepreneur. Hence total employment income could only fall for one reason: that the set $N \backslash \cup_{j \in E} G_{j}$ shrinks and the set $\cup_{j \in E} G_{j} \backslash j$ grows, i.e. some who were previously managed by employees are now directly managed by entrepreneurs. But any such individuals must be managed by the new entrepreneur, given that no other entrepreneur's value changed. Therefore, they belong, post-entry, to $\hat{G}_{h}$, so that $\hat{v}_{(1) j}=\hat{v}_{h j}$. and $\hat{v}_{(2) j}=v_{(1) j}$. 
Then their contribution to the right-hand side above stays the same. Since $\|N\|-\|O\|=\|\hat{N}\|-\|\hat{O}\|$ and
\[ \sum_{i \in N \backslash O} w_{e_{i}^{*}\left(w^{*}\right)}^{*}(i) \leq \sum_{i \in \hat{N} \backslash \hat{O}} \hat{w}_{\hat{e}_{i}^{*}\left(\hat{w}^{*}\right)}^{*}(i), \]

average employee income weakly increases.

Pre-entry total entrepreneurial income is:

$$
\begin{aligned}
\sum_{i \in O}\left(w_{i}^{*}(i)+\pi_{i}\left(s^{*}\right)\right) & =\sum_{i \in O} v_{(1) i}+\sum_{i \in O} \sum_{j \in G_{i} \backslash i}\left(v_{(1) j}-v_{(2) j}\right) \\
& =\sum_{i \in O} v_{(1) i}+\sum_{i \in \cup_{j \in E} G_{j} \backslash j}\left(v_{(1) i}-v_{(2) i}\right) .
\end{aligned}
$$

Incumbent entrepreneurs $i$ for whom $v_{(1) i}$ increases post-entry must become employees of the new entrepreneur, but the definition of entrepreneurial entry rules this scenario out (such entry does not replace existing entrepreneurs). Therefore, the first term remains constant. The set $\cup_{j \in E} G_{j} \backslash j$ of employees for whom an incumbent entrepreneur is the best manager can only shrink after the new entrepreneur appears. The highest conditional productivities for those who remain in this set post-entry cannot have increased (else they would now be managed best by the new entrepreneur). The second-highest conditional productivities cannot have decreased. Hence the second term diminishes, so that total income of the incumbent entrepreneurs decreases. Since $\|O\|=\|\hat{O}\|$ and

$$
\sum_{i \in O}\left(w_{i}^{*}(i)+\pi_{i}\left(s^{*}\right)\right) \leq \sum_{i \in O}\left(\hat{w}_{i}^{*}(i)+\hat{\pi}_{i}\left(\hat{s}^{*}\right)\right)
$$

average income of incumbent entrepreneurs weakly falls.

\section{P9}

Suppose entrepreneurial entry is imitative. Then, by definition, there exists for some incumbent entrepreneur $i$ an employee $j \in G_{i}$ who switches to the new entrepreneur, i.e. $j \in \hat{G}_{h}$. Then $\hat{v}_{(1) j}=\hat{v}_{h j}>v_{i j}=v_{(1) j}$ and $\hat{v}_{(2) j}=\hat{v}_{i j}>v_{(2) j}$. Recalling that

$$
\sum_{i \in N \backslash O} w_{e_{i}^{*}\left(w^{*}\right)}^{*}(i)=\sum_{i \in N \backslash \cup_{j} \in O G_{j}} v_{(1) i}+\sum_{i \in \cup_{j} \in O G_{j} \backslash j} v_{(2) j},
$$


and also that the identities of employees are unchanged and nothing can decrease on the right-hand side, the strict increase in $v_{(1) j}$ and $v_{(2) j}$ implies a strict increase in the average employee income.

Because $i$ loses a member of $G_{i} \backslash i$ and

$$
\sum_{i \in O}\left(w_{i}^{*}(i)+\pi_{i}\left(s^{*}\right)\right)=\sum_{i \in O} v_{(1) i}+\sum_{i \in O} \sum_{j \in G_{i} \backslash i}\left(v_{(1) j}-v_{(2) j}\right)
$$

(while incumbent entrepreneurs cannot become best managers for anyone new as a result of entrepreneurial entry), the average average income of incumbent entrepreneurs strictly decreases.

\section{P10}

We construct the equilibrium $s^{*}$ as follows. Manager assignments $r^{*}$ are value-maximizing (satisfy $\mathrm{P} 6$ ), and employer choices $e^{*}$ select the highest wage offer (or, in case of a tie, the offer from the individual who is the better manager). The high bid for each $i \in N$ is $w_{(1)}^{*}(i)=v_{(2) i}+$ $\sum_{j \in G_{i}}\left(v_{(1) j}-v_{(2) j}\right)$, and is made by the person who is the best manager for $i$, i.e. $h$ such that $v_{h i}=v_{(1) i}$. The high bid is matched by the person who is the second-best manager for $j$, i.e. $h^{\prime}$ such that $v_{h^{\prime} i}=v_{(2) i}$.

The resulting firms are, for $i=1, \ldots, N, F_{i}\left(s^{*}\right)=\bar{G}_{i}$ if $i \in G_{i}$ and $F_{i}\left(s^{*}\right)=\varnothing$ otherwise, which means $s^{*}$ is hierarchical. We argue that $s^{*}$ is also Nash. No one can have an incentive to deviate by reorganizing an efficient equilibrium firm (change $r_{i}^{*}$ ). Accepting the highest wage offer is always best for non-entrepreneurs and, given the form of the winning offers, implies that $i$ becomes an entrepreneur if and only if $i \in G_{i}$. In $F_{i}\left(s^{*}\right), i$ adds at least $v_{i i}+\sum_{j \in G_{i}}\left(v_{(1) j}-v_{(2) j}\right)$ under the manager assignment $r_{i}^{*}$. If $i \in G_{i}$, then $v_{i i}=v_{(1) i}$, so $i$ can earn more income through contributing to profit in $F_{i}\left(s^{*}\right)$ than from the highest competing wage offer. Conversely, suppose $i \notin G_{i}$, but $i$ turns down the highest wage offer to become an entrepreneur. Because the entrepreneur's income is independent of the wage paid to self, this scenario is akin to an increase in wage offers. We may therefore confine ourselves to considering changes in wage offers.

Observe first that $i$ cannot profitably reduce wage offers. Suppose $i$ is an entrepreneur. Employing $j \in F_{i}\left(s^{*}\right)$ at wage $w_{(1)}^{*}(j)$ is strictly profitable for $i$, since $j \in \bar{G}_{i}$ and $j \in G_{k}$ implies $k \in \bar{G}_{i}$, so that $j$ is assigned to the best manager and directly adds $v_{(1) j}>v_{(2) j}$ to the firm $F_{i}\left(s^{*}\right)$. Moreover 
$G_{j} \subseteq \bar{G}_{i}$, hence $j$ indirectly adds at least $\sum_{x \in G_{i}}\left(v_{(1) x}-v_{(2) x}\right)$ to $F_{i}\left(s^{*}\right)$ as the best manager for the group $G_{j}$. Offering less than $w_{(1)}^{*}(j)$ loses $j$ to the previously second-highest bidder and therefore reduces $i$ 's profit. If $i$ is not an entrepreneur, then none of $i$ 's wage offers are accepted, and lowering them does not change anything for $i$.

No more can $i$ profitably increase wage offers. If $i$ is to benefit from raising offers, they must be accepted and add to membership in $F_{i}\left(s^{*}\right)$. Suppose $i$ attracts the group $C$ from outside $F_{i}\left(s^{*}\right)$. Then $i$ must offer strictly more than $w_{(1)}^{*}(j)$ to each $j \in C$ :

$$
\begin{aligned}
\sum_{j \in C} w_{i}(j) \geq \sum_{j \in C} w_{(1) j}^{*} & =\sum_{j \in C} v_{(2) j}+\sum_{j \in C} \sum_{x \in G_{j}}\left(v_{(1) x}-v_{(2) x}\right) \\
& =\sum_{j \in C} v_{(2) j}+\sum_{x \in \cup_{j \in C} G_{j}}\left(v_{(1) x}-v_{(2) x}\right) .
\end{aligned}
$$

Since $F_{i}\left(s^{*}\right)$ initially included all ideal managers for its employees, members of $C$ can only add value directly or through managing other members of $C$. I.e. their contribution to $F_{i}\left(s^{*}\right)$ is $\sum_{j \in C} \max _{k \in F_{i}\left(s^{*}\right)} v_{k j}$. Denote the subset of $C$ with best managers in $C$ by $C_{0} \equiv\left\{x \in C\right.$ s.t. $x \in G_{j}$ with $\left.j \in C\right\}$. Because $F_{i}\left(s^{*}\right)$ already included anyone whose ideal manager is in $F_{i}\left(s^{*}\right)$, all other members of $C$, i.e. $j \in C \backslash C_{0}$, cannot make a direct contribution greater than $v_{(2) j}$ to $F_{i}\left(s^{*}\right)$. The contribution $C$ makes to $F_{i}\left(s^{*}\right)$ is therefore at most:

$$
\sum_{j \in C_{0}} v_{(1) j}+\sum_{j \in C \backslash C_{0}} v_{(2) j} \geq \sum_{j \in C} \max _{k \in F_{i}\left(s^{*}\right)} v_{k j} .
$$

Because $C_{0} \subseteq \cup_{j \in C} G_{j}$,

$$
\begin{aligned}
\sum_{j \in C} w_{i}(j) & \geq \sum_{j \in C} v_{(2) j}+\sum_{x \in \cup_{j \in C} G_{j}}\left(v_{(1) x}-v_{(2) x}\right) \\
& =\sum_{j \in C_{0}} v_{(2) j}+\sum_{j \in C_{0}}\left(v_{(1) j}-v_{(2) j}\right)+\sum_{j \in C \backslash C_{0}} v_{(2) j}+\sum_{x \in \cup_{j \in C} G_{j} \backslash C_{0}}\left(v_{(1) x}-v_{(2) x}\right) \\
& =\sum_{j \in C_{0}} v_{(1) j}+\sum_{j \in C \backslash C_{0}} v_{(2) j}+\sum_{x \in \cup_{j \in C} G_{j} \backslash C_{0}}\left(v_{(1) x}-v_{(2) x}\right) \\
& \geq \sum_{j \in C} \max _{k \in F_{i}\left(s^{*}\right)} v_{k j}+\sum_{x \in \cup_{j \in C} G_{j} \backslash C_{0}}\left(v_{(1) x}-v_{(2) x}\right) .
\end{aligned}
$$

This means $i$ would pay more for $C$ than its members can contribute to $F_{i}\left(s^{*}\right)$; raising bids is not profitable. 
Hence individuals are optimizing in all three strategic components in $s^{*}$, and $s^{*}$ is a hierarchical equilibrium.

\section{References}

[1] Arabsheibani, G; de Meza, D.; Maloney, J.; Pearson, B. (2000). And a Vision Appeared unto Them of a Great Profit: Evidence of SelfDeception among the Self-Employed. Economics Letters 67, 35-41.

[2] Benz, M.; Frey, B. (2008). Being Independent is a Great Thing: Subjective Evaluations of Self-Employment and Hierarchy. Economica 75, 362-383.

[3] Blanchflower, D.; Oswald, A.; Stutzer, A. (2001). Latent Entrepreneurship Across Nations. European Economic Review 45, 680-691.

[4] Bohacek, R. (2006). Financial Constraints and Entrepreneurial Investment. Journal of Monetary Economics 53, 2195-2212.

[5] Camerer, C.; Lovallo, D. (1999). Overconfidence and Excess Entry: An Experimental Approach. American Economic Review 89, 306-318.

[6] Crawford, V.P., E.M. Knoer (1981). "Job Matching with Heterogeneous Firms and Workers." Econometrica 49, 437-450.

[7] de Meza, D.; Southey, C. (1996). The Borrower's Curse: Optimism, Finance and Entrepreneurship. Economic Journal 106, 375-386.

[8] Dutta, B., J. Masso (1997). "Stability of Matchings when Individuals Have Preferences over Colleagues." Journal of Economic Theory 75, 464475 .

[9] Ellickson, B.; Grodal, B.; Scotchmer, S.; Zame, W.R. (1999). Clubs and the Market. Econometrica 67, 1185-1217.

[10] Evans, D., B. Jovanovic (1989). An Estimated Model of Entrepreneurial Choice under Liquidity Constraints. Journal of Political Economy 97, 808-827. 
[11] Farrell, J.; Scotchmer, S. (1988). Partnerships. Quarterly Journal of Economics 103, 279-297.

[12] Frank, M. Z. (1988). An Intertemporal Model of Industrial Exit. Quarterly Journal of Economics 103, 333-344.

[13] Hamilton, B. (2000). Does Entrepreneurship Pay? An Empirical Analysis to the Returns of Self-Employment. Journal of Political Economy 108, 604-631.

[14] Hatfield, J.W.; Milgrom, P.R. (2005). Matching with Contracts. American Economic Review 95, 913-931.

[15] Kelso, A.S., Jr.; Crawford, , V.P. (1982). Job Matching, Coalition Formation, and Gross Substitutes. Econometrica 50, 1483-1504.

[16] Kihlstrom, R., J. Laffont (1979). A General Equilibrium Entrepreneurial Theory of Firm Formation Based on Risk Aversion. Journal of Political Economy 87, 719-748.

[17] Koellinger, P.; Minniti, M.; Schade, C. (2007). I Think I Can, I Think I Can: Overconfidence and Entrepreneurial Behavior. Journal of Economic Psychology 28, 502-527.

[18] Kremer, M. (1993). The O-Ring Theory of Economic Development. Quarterly Journal of Economics 108, 551-575.

[19] Laussel, D., M. Le Breton (1995). A General Equilibrium Theory of Firm Formation Based on Individual Unobservable Skills. European Economic Review 39, 1303-1319.

[20] Lazear, E. P. (2004). Balanced Skills and Entrepreneurship. American Economic Review 94, 208-211.

[21] Lazear, E. P. (2005). Entrepreneurship. Journal of Labor Economics 23, $649-680$.

[22] Lucas, R. E. (1978). On the Size Distribution of Business Firms. Bell Journal of Economics 9, 508-523.

[23] Ma, J. (2001). Job Matching and Coalition Formation with Utility and Disutility of Co-Workers. Games and Economic Behavior 34, 83-103. 
[24] Polkovnichenko, V. (2003). Human Capital and the Private Equity Premium. Review of Economic Dynamics 6, 831-845.

[25] Pycia, M. (2005). Many-To-One Matching without Substitutability. Working Paper.

[26] Rees, H.; Shah, A. (1986). An Empirical Analysis of Self-Employment in the U.K. Journal of Applied Econometrics 1, 95-108.

[27] Rosen, S. (1982). Authority, Control, and the Distribution of Earnings. Bell Journal of Economics 13, 311-323.

[28] Roth, A.E. (1984). Stability and Polarization of Interests in Job Matching. Econometrica 52, 47-57.

[29] Sherstyuk, K. (1999). Multisided Matching Games with Complementarities. International Journal of Game Theory 28, 489-509.

[30] Vereshchagina, G.; Hopenhayn, H. (2009). Risk Taking by Entrepreneurs. American Economic Review 99, 1808-1830. 